\title{
OS FENÔMENOS DE SEGREGAÇÃO E EXCLUSÃO SOCIAL NA SOCIEDADE DO CONHECIMENTO
}

\author{
JUAN CARLOS TEDESCO
}

Diretor do Instituto Internacional de Planificación de la Educación, Filial da Unesco-

Buenos Aires/Argentina

j.tedesco@iipe-buenosaires.org.ar

\begin{abstract}
RESUMO
O artigo analisa os novos fenômenos de desigualdade e exclusão desencadeados pela utilização intensiva do conhecimento e da informação na organização do trabalho, por um lado, e, nas instituições políticas e culturais, pelo outro. A partir dessa análise são apresentadas algumas conseqüências para a educação, particularmente as que se referem ao papel desta em relação à mobilidade social, aos riscos da privatização dos circuitos nos quais se reproduz e distribuio conhecimento socialmente mais significativo, bem como em relação às mudanças na atuação da escola do ponto de vista do processo de socialização.

MOBILIDADESOCIAL - DESIGUALDADESSOCIAIS - TRABALHO-EDUCAÇÃO
\end{abstract}

\section{ABSTRACT}

THEPHENOMENA OFSEGREGATIONAND SOCIAL EXCLUSIONIN THEKNOWLEDGE SOCIETY. This article analyzes the new phenomena of inequality and exclusion resulting from the intensive use of knowledge and information in the organization of work, on one hand, and in political and cultural institutions, on the other. Based on this analysis, some consequences for education are presented, particularly those regarding its role in relation to social mobility, the risks of privatizing the circuits in which socially significant knowledge is reproduced and distributed, as well as to changes in schools' work from the point of view of the socialization process. SOCIAL MOBILITY-SOCIALLYDISADVANTAGE-WORK-EDUCATION

Versão traduzida deste artigo está disponível em : www.mec.gov.br/semtec/escjov.shtm 
Já se disse repetidamente que o fim do século e a entrada no novo milênio estão associados a um profundo processo de transformação social. Não estamos vivendo uma das periódicas crises conjunturais do modelo capitalista de desenvolvimento, mas a aparição de novas formas de organização social, econômica e política'. A crise atual, conseqüentemente, é uma crise estrutural, cuja principal característica é que as dificuldades de funcionamento se produzem simultaneamente nas instituições responsáveis pela coesão social - o Estado-Providência -, nas relações entre economia e sociedade - a crise do trabalho - e nos modos de constituição das identidades individuais e coletivas - crise de sujeito (Fitoussi, Rosanvallon, 1996).

Um dos aspectos centrais da nova organização social que se está conformando a partir desta crise é que o conhecimento e a informação estariam substituindo os recursos naturais, a força e o dinheiro, como variáveis-chave da geração e distribuição do poder na sociedade. Ainda que o conhecimento tenha sido sempre uma fonte de poder, passaria a ser, agora, sua fonte principal, o que produziria efeitos marcantes sobre a dinâmica interna da sociedade (Thurow, 1996).

As primeiras análises sobre o papel do conhecimento e da informação como variáveis centrais do poder foram significativamente otimistas sobres suas potencialidades democratizadoras. Alvin Toffler foi, sem dúvida alguma, o representante mais importante dessa corrente. Suas análises baseavam-se no caráter essencialmente democrático que tem tanto a produção como a distribuição dos conhecimentos e das informações. Segundo Toffler, o conhecimento é infinitamente ampliável. Seu uso não o desgasta; ao contrário, pode produzir ainda mais conhecimento. A produção de conhecimentos requer, além disso, um ambiente de criatividade e de liberdade, oposto a toda tentativa autoritária ou burocrática de controle do poder. Deste ponto de vista, a utilização intensiva de conhecimentos produz a dissolução das formas burocráticas de gestão, porque obriga a renovar permanentemente as linhas de decisão em razão da acumulação e do intercâmbio de conhecimentos. Por último, a distribuição de conhecimentos é muito mais democrática que a distribuição de qualquer outro fator tradicional de poder, já que "o fraco e o pobre podem adquiri-lo" (Toffler, 1990).

De uma perspectiva mais pedagógica, a centralidade do conhecimento também inspirou inicialmente algumas posturas otimistas sobre o futuro da sociedade,

I Ver, entre outros, Drucker, 1993; Minc, 1994; Toffler, 1990; Gorz, 1997; Castells, 1997; Boltansky, Chiapello, 1999. 
já que a idéia segundo a qual o desenvolvimento cognitivo tem alguma influência nas condutas e no comportamento das pessoas esteve sempre na base das propostas de mudança social. Ensinar a pensar bem, a pensar melhor, estava associado geralmente à idéia de formar um ser mais "humano". As últimas versões dessa abordagem provêm de pensadores vinculados ao desenvolvimento de enfoques interdisciplinares que permitam compreender adequadamente a complexidade dos fenômenos. A suposição básica deste ponto de vista é que as pessoas capazes de compreender a complexidade atuariam de maneira mais responsável e consciente.

Segundo Edgar Morin, por exemplo, a inteligência que só sabe separar atrofia as faculdades de compreensão e de reflexão, eliminando assim as possibilidades de um juízo correto ou de uma perspectiva a longo prazo. Uma inteligência incapaz de perceber o contexto e o complexo planetário torna as pessoas cegas, inconscientes e irresponsáveis (1999).

Mas o otimismo inicial desses enfoques foi substituído rapidamente por visões mais realistas e complexas sobre os efeitos democratizadores dos novos padrões de organização social e econômica baseados no conhecimento e na informação. A hipótese mais geral, sobre a qual queremos apoiar nossa análise, sustenta que uma sociedade baseada no uso intensivo de conhecimentos produz simultaneamente fenômenos de mais igualdade e de mais desigualdade, de maior homogeneidade e de maior diferenciação.

Neste texto tentaremos analisar esses fenômenos, baseados no impacto da utilização da informação e dos conhecimentos na organização do trabalho por um lado, e nas instituições políticas e culturais por outro. Com base nessa análise, na última parte do texto serão apresentadas algumas conseqüências do ponto de vista da educação.

\section{O AUMENTO DA DESIGUALDADE E DA HOMOGENEIDADE}

Em primero lugar, ressalte-se que um dos fenômenos mais importantes nas transformações sociais atuais é o aumento significativo da desigualdade social.

A evolução da distribuição de renda no mundo nas últimas décadas permite observar que, em geral, mantêm-se altos os níveis de concentração de riqueza nos países em desenvolvimento, e que os países ricos atravessam um processo significativo de concentração de renda que os aproxima do perfil dos países em desenvolvimento.

Apesar de existir um consenso quanto ao reconhecimento da complexidade desses processos, também se admite que um dos fatores fundamentais associado 
ao aumento da desigualdade é a transformação na organização do trabalho. A esse respeito, as informações disponíveis permitem verificar que a incorporação de novas tecnologias ao processo produtivo está associada à eliminação de numerosos postos de trabalho. Nesse contexto, a maior parte dos novos postos de trabalho não é criada nos setores tecnologicamente mais avançados, mas nos serviços em que o custo do trabalho representa uma proporção importante do preço do produto.

Essa diferença no ritmo de criação de postos de trabalho está associada a diferenças salariais. Enquanto os setores de alta produtividade podem ter políticas salariais generosas, os setores de serviços, nos quais o vínculo entre salários e emprego é muito alto, estão obrigados a aumentar moderadamente os salários, caso queiram ampliar o número de empregos. Essa dinâmica, em que o emprego diminui nos setores que podem pagar bons salários e aumenta naqueles que pagam salários modestos, explica as razões pelas quais "a recomposição do emprego em função da evolução tecnológica aumenta a desigualdade" (Foucauld; Piveteau, 1995).

Em segundo lugar, as transformaç̃̃es na organização do trabalho estão provocando não só o aumento nos níveis de desigualdade como a aparição de um novo fenômeno social: a exclusão da participação no ciclo produtivo. Nesse sentido, os estudos sobre as possibilidades oferecidas pelas novas formas de organização do trabalho indicam que elas poderiam incorporar de maneira estável só uma minoria de trabalhadores, para os quais haveria garantias de segurança no emprego em troca de uma identificação total com a empresa e com suas exigências de reconversão permanente. Para o resto, em compensação, seriam criadas condições de extrema precariedade, expressas por formas tais como contratos temporários, trabalhos interinos, trabalhos de tempo parcial e, no extremo destas situações, o desemprego.

Com a exclusão no trabalho, produzir-se-ia uma exclusão social mais geral ou, como preferem dizer alguns autores, uma "desfiliação" em relação às instâncias sociais mais significativas (Castel, 1995).

O fenômeno da exclusão social provoca, deste ponto de vista, uma modificação fundamental na estrutura da sociedade. Segundo esse enfoque, estaríamos vivendo um momento de transição:

a. de uma sociedade vertical, baseada em relações sociais de exploração entre os que ocupam posições superiores, em face dos que ocupam as posições inferiores; 
b. a uma sociedade horizontal, em que o importante não é tanto a hierarquia como a distância em relação ao centro da sociedade.

A exclusão tende, dessa maneira, a substituir a relação de exploração. A comparação entre ambos os modelos de relações permite notar que os vínculos entre exploradores e explorados são completamente diferentes dos que se estabelecem entre incluídos e excluídos.

Exploradores e explorados pertencem à mesma esfera econômica e social, já que os explorados são necessários para manter o sistema. A tomada de consciência da exploração pode provocar, além disso, uma reação de mobilização coletiva e de conflito organizado pelas instituições representativas dos explorados, como os sindicatos, os partidos políticos etc.

A exclusão, em compensação, não implica relação, mas sim divórcio. A tomada de consciência da exclusão não gera uma reação organizada de mobilização. Na exclusão não há grupo contestador, nem objeto preciso de reivindicação, nem instrumentos concretos para impô-la. Como resumiu recentemente um analista desses fenômenos, enquanto a exploração é um conflito, a exclusão é uma ruptura (Castel, 1995, p. 147).

Mas a complexidade destes processos evidencia-se quando constatamos que o aumento da desigualdade e a aparição da exclusão coexistem com uma significativa diminuição da importância das hierarquias tradicionais. Na organização do trabalho baseada na utilização intensiva de conhecimentos, tende-se a substituir as tradicionais pirâmides de relações de autoridade, próprias do modelo fordista de produção, por redes de relações cooperativas. Nesse esquema, todas as fases do processo produtivo são importantes, e o pessoal, seja em que nível da hierarquia esteja, desempenha um papel crucial.

A transformaç̧ão das pirâmides hierárquicas tradicionais, no entanto, não implica a desaparição da desigualdade nem das relações de poder no interior das organizações. A maior flexibilidade está provocando a aparição de novas e mais complexas formas de relações de trabalho, em que a tensão mais importante é a que se produz entre as demandas de lucro em curto prazo, por parte dos acionistas, e as demandas de planejamento, compromisso e confiança que reclamam as pessoas que investem todas suas capacidades pessoais no processo produtivo.

Richard Sennett, em um livro recente sobre as conseqüências das transformações na organização do trabalho sobre a personalidade, apresentou alguns desses problemas de maneira muito acentuada. A respeito do tema que mais nos 
interessa neste texto - o tema da eqüidade - Sennett sustenta que, nos atuais processos de descentralização das unidades produtivas, o poder central age através de outros mecanismos igualmente poderosos, mas amorfos. Um dos mecanismos é a fixação de metas e resultados que, geralmente, são superiores às capacidades reais e obrigam a produzir muito mais do que o habitual. A respeito da substituição das hierarquias tradicionais, Sennett sustenta que, com as mudanças contínuas de trabalho e de tarefas, produzem-se movimentos novos e ambíguos:

Na medida em que as hierarquias piramidais vão sendo substituídas por estruturas mais flexíveis, as pessoas que mudam de trabalho experimentam, com grande freqüência, o que os sociólogos denominaram "movimentos ambiguamente laterais". São movimentos em que as pessoas se movem, em realidade, para o lado, ainda que creiam mover-se para cima na rede flexível [ . . . ] Outros estudiosos da mobilidade social insistem nas chamadas "perdas retrospectivas" em uma rede flexível. Uma vez que as pessoas que se arriscam a mover-se em organizações flexíveis costumam ter pouca informação confiável sobre o que leva a uma nova posição, só retrospectivamente percebem que tomaram decisões equivocadas. [...] a mobilidade profissional na sociedade contemporânea é, a miúdo, um processo ilegível.

\section{$[\ldots]$}

A cultura moderna do risco caracteriza-se pela mobilidade, porque não se mover é sinônimo de fracasso e a estabilidade parece quase uma morte em vida. Portanto, o destino importa menos que o ato de partir. Imensas forças econômicas e sociais dão forma à insistência de ir adiante; a desordem das instituições, o sistema de produção flexível, realidades materiais que fazem água. Ficar quieto equivale a ficar fora do jogo. [...] Não é que a desigualdade e a diferença social tenham desaparecido; nada mais distante do que isso. Ao contrário, é como se, ao entrar em movimento, de repente fosse suspensa a realidade pessoal; ninguém é tão calculista, nem escolhe tão racionalmente, mas espera que algo surja com a mudança. (Sennett, 2000, p.89-91)

Nesse sentido, é interessante retomar uma hipótese provocativa apresentada por Cohen, segundo a qual as economias de conhecimento intensivo e produtoras de idéias são menos eqüitativas que as economias de mão-de-obra intensiva e fabricantes de objetos. A tendência a excluir os que não têm idéias parece ser mais forte que a tendência a excluir os que não têm riquezas (1997). Na base dessa situação encontra-se o comportamento inspirado na hipótese do "erro zero". Como se sabe, esta hipótese foi elaborada a partir do acidente da nave espacial Challenger, em que todo o esforço e o investimento realizados nesse projeto se perderam por uma simples falha em uma conexão secundária. 
A análise desse exemplo permite constatar que, no marco das atuais tecnologias de produção, a menor disfunção de uma das partes ameaça a produção em seu conjunto. Conseqüentemente, os níveis de qualidade e de qualificação dos trabalhadores que se desempenham em um mesmo processo produtivo devem ser semelhantes. Os melhores tendem a agrupar-se com os melhores, e os medíocres com os medíocres. Este fenômeno, relativamente normal e conhecido, tende a exacerbar-se com a expansão das novas tecnologias e a possibilidade de descentralizar e de tornar externos segmentos importantes da produção. Dessa forma, cada unidade de produção transforma-se em um subconjunto homogêneo de um processo produtivo muito mais amplo.

Como indicador dessa tendência, Cohen resume em seu livro as informações disponíveis a respeito da França onde, entre 1986 e 1992, a homogeneidade da força de trabalho, nas empresas que ocupam mais de dez pessoas, aumentou em mais de 20\%. Nesse contexto, a segmentação e a desigualdade mudam de sentido. Na economia capitalista tradicional, cada segmento social era uma categoria e "a desigualdade se produzia entre grupos sociais". Agora, em compensação, a segmentação se produz dentro de cada grupo social. De acordo com os dados apresentados por Cohen, por exemplo, mais de $70 \%$ do fenômeno da desigualdade americana se explica pela diferença de salários entre trabalhadores jovens, entre graduados ou entre trabalhadores da indústria.

Em resumo, enquanto as desigualdades tradicionais eram fundamentalmente intercategoriais, as novas desigualdades são intracategoriais. Do ponto de vista subjetivo, uma das características mais importantes desse fenômeno é a dificuldade de auto-aceitação, já que ele põe em cheque a representação que cada um tem de si mesmo. As novas desigualdades provocam, por isso, um sofrimento muito mais profundo, porque são percebidas como um fenômeno mais pessoal que socioeconômico e estrutural (Fitoussi, Rosanvallon, 1996).

\section{A IDEOLOGIA DA DESIGUALDADE}

O aumento da desigualdade, descrito sumariamente nas seções anteriores, vem acompanhado por um aumento igualmente importante das teorias que tendem a justificar o fenômeno. Enquanto no modelo capitalista tradicional a pobreza ou a condição assalariada podiam ser percebidas como conseqüências de uma ordem social injusta, no novo capitalismo tendem a ser associadas à natureza das coisas e, em última instância, à responsabilidade pessoal. Não é casual, por isso, observar o ressurgimento de idéias que tendem a explicar a vigência de determina- 
dos padrões de conduta, dos níveis de desenvolvimento cognitivo pessoal e do lugar na estrutura social por fatores genéticos.

Uma das versões mais difundidas deste neodarwinismo social é a do livro de Herrnstein e Murray ( 1994), baseado no pressuposto de que a habilidade cognitiva será a variável decisiva na estrutura social que se está conformando para o novo século e, segundo o qual, essa habilidade é fundamentalmente hereditária. Alguns cientistas sociais assumiram esse enfoque que, paradoxalmente, anula qualquer possibilidade de análise social das condutas humanas. Francis Fukuyama, por exemplo, sustenta, em um de seus mais recentes ensaios, que os comportamentos sociais se explicam por fatores genéticos e espera ainda que, nas próximas décadas, sejam descobertas novas relações entre alguns outros comportamentos e o código genético. Para Fukuyama (1999), como para outros ensaístas dessa mesma corrente, fenômenos tais como criminalidade, dependência química, alcoolismo, promiscuidade, separações, divórcios e outras "condutas desviadas" seriam explicados por fatores genéticos-hereditários e, portanto, dificilmente modificáveis através de políticas sociais.

Um exemplo dessa postura pode-se ver nos seguintes parágrafos :

A compreensão do substrato natural em que as relações sociais são construídas permite começar a elaborar conexões causais entre alguns dos fenômenos que temos documentado. A mais óbvia delas é aquela entre a família desestruturada e o abuso de crianças [...] A desestruturação familiar está também fortemente associada à criminalidade [...] Há evidências substanciais de que, além de mais promíscuos, os jovens de sexo masculino são significativamente mais agressivos e violentos do que mulheres e homens mais velhos; algo que decorre mais de seu perfil psicológico do que da cultura. (p.34-35)

A desigualdade justificada com base nos resultados da pesquisa genética é um dos principais exemplos acerca do papel que poderá desempenhar o conhecimento na determinação da estrutura social. A informação genética permitirá predizer trajetórias de vida com muito mais precisão do que no passado, e a utilização dessa informação tem potencialidades enormes sobre todo o sistema de relações sociais $^{2}$ (Rifkin, 1998).

2 Uma das primeiras e mais importantes reações internacionais ante as conseqüências do desenvolvimento da biotecnologia constitui a Declaração Universal sobre o Genoma Humano e os Direitos Humanos, aprovada em I I de novembro de 1997 pela $29^{a}$ Reunião da Conferência Geral da Unesco. 
Não só as companhias de seguros podem usar essa informação para definir que tipo de tratamento oferecerão aos assegurados, como os empregadores podem também aplicar esses resultados em suas políticas de recrutamento de pessoal, as escolas, no recrutamento de alunos etc. Abre-se, assim, a possibilidade de uma sociedade organizada em novas e mais virulentas formas de discriminação, baseadas no perfil genético de cada um.

A disponibilidade de informação genética diminui a possibilidade de continuar administrando justiça segundo o princípio do "véu de ignorância", apresentado por Rawls, (1978), em sua teoria da justiça . A justiça no Estado-Providência, e em todas as formas de solidariedade, funciona sobre a base desse véu de ignorância que não indaga sobre as particularidades de cada indivíduo. Essa ignorância contribui para a coesão e para socialização. Ao contrário, quando as informações sobre as particularidades de cada indivíduo se multiplicam, põe-se em marcha um mecanismo de "dessolidarização", de ruptura da coesão e de enfraquecimento do papel da socialização (Rosanvallon, 1995; Fitoussi, Rosanvallon, 1996).

Diante dessas tendências e como resposta às ideologias neoconservadoras, está-se gerando um novo pensamento democrático, baseado na idéia de que eliminar a desigualdade não é contraditório como respeito à diversidade. De acordo com tais postulados, a justiça e a solidariedade são elementos básicos para garantir o caráter sustentado do desenvolvimento social.

Mas esses princípios de justiça e eqüidade já não podem ser aplicados da mesma maneira que no passado. A justiça, por exemplo, não pode estar baseada na idéia de tratar a todos da mesma maneira. A justiça, particularmente a justiça social, deve tirar a venda que cobre seus olhos e que a impede de ver a quem se dirige, e tratá-lo de maneira mais adequada a sua situação.

A maior disponibilidade de informação pode também ser a base de estratégias de ações sociais mais eficazes para o sucesso da justiça e não, como sugerem os enfoques conservadores, um fator de discriminação. Mas esse novo enfoque da justiça social está intimamente associado ao fortalecimento da dimensão política da sociedade e, em particular, da democracia, porque somente com um forte sentido de pertinência coletiva é possível aceitar a idéia da redistribuição direta dos bens (Fitoussi, Rosanvallon, 1996). Desse ponto de vista, é muito importante vincular a análise das tendências no âmbito da organização do trabalho com as transformações no âmbito sociopolítico, em que o tema principal é o que se refere às transformações no Estado-Nação. 


\section{A CRISE DO ESTADO-NAÇÃO}

Uma das características mais importantes das mudanças na dimensão política é a que está relacionada com os processos de "deslocação" e "realocação" das pertinências e das identidades nacionais e culturais. Associada ao processo de globalização econômica, há uma tendência a construir entidades políticas supranacionais, capazes de enfrentar os desafios postos tanto em nível planetário como multinacional, tais como volumes crescentes de transações financeiras internacionais, problemas derivados do cuidado com meio ambiente (buraco na camada de ozônio, reaquecimento da crosta terrestre etc.), expansão do delito internacional (narcotráfico, prostituição etc.) e expansão da Internet como veículo de circulação de informações sem regulamentação possível em nível nacional.

Como resultado desses processos, o conceito de cidadania associado a $\mathrm{Na}$ ção (Schnapper, 1994) começa a perder significado. Em seu lugar, aparecem tanto a adesão a entidades supranacionais como também, ao contrário, uma volta ao sentido comunitário local, em que a integração se define fundamentalmente como integração cultural e não como integração política.

Essa mudança no conceito de cidadania tem enormes implicações. A aparição do local e do supranacional como novos espaços de participação social está associada a fenômenos de ruptura da ação política tal como concebida até agora. A construção de um conceito de cidadania mundial, de cidadania planetária, exige um conceito de solidariedade vinculado à pertinência ao gênero humano e não a alguma de suas formas particulares. Essa construção enfrenta, no entanto, enormes dificuldades, a maioria delas vinculada a formas por meio das quais se produz o processo de globalização.

Do ponto de vista econômico, a globalização não significa só que os capitais podem mover-se rápida e livremente por todo o planeta. $\bigcirc$ fenômeno socialmente mais importante é que, como as empresas podem instalar-se em qualquer parte do mundo e manter-se conectadas através de redes de informação, elas tendem a radicar-se ali onde os custos são menores. Esse fenômeno produz o que se denominou "uma espiral descendente de redução de custos sociais", que tende a debilitar a capacidade dos Estados nacionais para manter os níveis tradicionais de benefícios sociais e de bem-estar (Castells, 1997). A globalização econômica, em síntese, reduz a capacidade do Estado para definir sua política monetária, seu orçamento, sua arrecadação de impostos e a satisfação das necessidades sociais de sua população. 
Ao estar baseada fundamentalmente na lógica econômica e na expansão de mercado, a globalização rompe com os compromissos locais e as formas habituais de solidariedade e de coesão com nossos semelhantes. As elites que atuam em nível global tendem a comportar-se sem compromisso com os destinos das pessoas afetadas pelas conseqüências da globalização. A resposta a este comportamento por parte dos excluídos é o refúgio na identidade local, em que a coesão do grupo se apóia na rejeição aos "externos".

Nesse sentido, numerosos diagnósticos da sociedade atual mostram que a ruptura dos vínculos tradicionais de solidariedade, provocada pelo processo de globalização, gerou novas formas de exclusão, de solidão e de marginalidade. As formas de associação e de expressão de alguns desses setores excluídos tendem a apoiar-se em valores de intolerância, de discriminação e de exacerbação dos particularismos. Enquanto na cúpula as elites que participam da economia supranacional criam o risco de que seu desapego à nação estimule um individualismo "associal", fundamentado na falta total de solidariedade, na base observam-se fenômenos regressivos de rejeição ao diferente, de xenofobia e de coesão autoritária.

Manuel Castells, em livro já citado, explica com clareza esse processo que dá lugar ao aparecimento do fenômeno atual do fundamentalismo e de Estados fundamentalistas. De acordo com sua análise, o Estado-Nação, para sobreviver à crise de legitimidade, cede poder e recursos aos governos locais e regionais. Nesse processo, perde capacidade para igualar os interesses diferentes e representar o "interesse geral". Esse processo deslegitima ainda mais o Estado, particularmente diante das minorias discriminadas, que buscam proteção nas comunidades locais ou em outro tipo de estruturas. Segundo Castells

... o que começou como um processo de "relegitimação" do Estado, mediante a passagem do poder nacional ao local, pode acabar aprofundando a crise de legitimação do Estado-nação e a tribalização da sociedade em comunidades construídas em torno de identidades primárias. (1997, p.304)

Em síntese, tanto as mudanças nos modelos de organização do trabalho, como as transformações nas estruturas de participação social e política estão estimulando a aparição de formas novas de segmentação e diferenciação social. A característica comum desses novos tipos de diferenciação é que se apóiam, seja em fatores naturais, como genes, inteligência ou etnia, seja em fatores culturais de forte conotação de adscrição, como a religião ou a língua.

Nesse contexto é possível compreender a ênfase que outorgam as análises prospectivas, inspiradas em objetivos democráticos, ao desenvolvimento da capaci- 
dade de conviver como condição da construção de uma ordem social sustentável (Delors, 1996). Fortalecer a coesão social sobre a base da aceitação consciente da existência do "outro", do diferente, converteu-se de novo no principal objetivo das instituições responsáveis pelo processo de socialização, particularmente da escola.

\section{A EDUCAÇÃO E OS DESAFIOS DO FUTURO}

A análise efetuada até aqui permitiu apreciar a importância das transformações que estão se registrando na estrutura econômica, política e cultural da sociedade. As formas emergentes de organização social apóiam-se no uso intensivo do conhecimento e das variáveis culturais de associação e participação social. Nesse contexto, as instâncias através das quais se produzem e se distribuem o conhecimento e os valores culturais - instituições educacionais, educadores, intelectuais em geral - ocuparam um lugar central não só na análise das novas configurações, como na definição de estratégias de intervenção social e política.

Não é possível, nos limites deste documento, efetuar uma análise exaustiva do papel da educação na sociedade. Limitar-nos-emos, então, a assinalar três pontos cruciais para a discussão e a análise posterior.

Em primeiro lugar, é preciso mencionar a mudança no papel da educação diante da mobilidade social. No capitalismo tradicional, como se sabe, a educação estava diretamente associada às possibilidades de mobilidade social. Ascender na hierarquia do sistema educativo significava ascender a níveis mais complexos do conhecimento e a posições mais altas na estrutura ocupacional. Mas à medida que a estrutura ocupacional de tipo piramidal tende a perder importância e as redes expandem-se como modelo de organização das instituições, diminui a importância da mobilidade social vertical e aumentam, em compensação, as oportunidades de mobilidade horizontal. A educação também modifica seu papel já que, por um lado, será a variável mais importante que permitirá entrar ou ficar fora do círculo no qual se definem e realizam as atividades socialmente mais significativas e, por outro, será necessário educar-se ao longo de toda a vida para poder adaptar-se aos requerimentos cambiantes do desempenho social e produtivo. No futuro, paradoxalmente, será necessária uma mobilidade muito intensa para manter-se na mesma posição.

Em segundo lugar, é preciso considerar o problema da democratização do acesso aos circuitos nos quais se produz e se distribui o conhecimento socialmente mais significativo. A privatização desses circuitos e sua apropriação por um grupo reduzido da população dariam lugar a uma espécie de neodespotismo ilustrado, 
incompatível com formas políticas democráticas de participação e controle social. Nesse sentido, as opções democráticas na política educacional deverão apoiar-se em um alto nível de confiança na capacidade de aprendizagem de todas as pessoas. Conseqüentemente, será necessário enfatizar mais que nunca o alcance universal da educação. Se, no passado, o sistema podia organizar-se em níveis que correspondiam a determinadas categorias sociais e de complexidade na organização do conhecimento, no futuro a democratização do acesso aos níveis superiores de análise de realidades e fenômenos complexos deve ser universal.

Esse acesso universal à compreensão de fenômenos complexos constitui a condição necessária para evitar a ruptura da coesão social e os cenários catastrofistas que potencialmente estão presentes nas tendências sociais atuais. Mas o acesso à compreensão de fenômenos complexos não pode estar associado a um determinado nível do sistema e, muito menos, a seus níveis superiores. A formação básica e universal deverá ser capaz de dotar o conjunto dos cidadãos dos instrumentos e das competências cognitivas necessárias para o desempenho de um cidadão ativo.

Em terceiro lugar, é preciso considerar a educação do ponto de vista do processo de socialização. Já não é possível pensar, como no passado, que as regulamentações virão exclusiva ou fundamentalmente de instituições como o Estado, a Igreja ou a família. Tampouco é possível pensar que haverá uma regulamentação espontânea baseada nos mecanismos do mercado, que assegure a coesão e a eqüidade necessárias para o desenvolvimento social sustentável.

As formas tradicionais de solidariedade estão perdendo importância. Numerosos testemunhos indicam a aparição e o risco de expansão rápida de uma sociedade atomizada, na qual o indivíduo isolado estaria em face de uma coletividade anônima. Estão aparecendo novas formas de solidariedade e associação: associações de bairro, "tribos" urbanas, gangues juvenis etc. Mas a solidariedade gerada por estas novas formas de agrupamento não está associada a movimentos integradores. A desaparição das formas tradicionais de pertinência provoca a aparição de uma nova obrigação, a de cada um gerar por si mesmo sua forma de inserção social (Foucauld, Piveteau, 1995).

Um exemplo claro dessa transformação é o caso da família, que mantém sua importância, mas já não é a família fixa e estável de antes. A trajetória familiar de uma pessoa pode atravessar fases diferentes: casal estável, família monoparental, união livre etc. Os parentes se transformam em uma combinação de laços eletivos e de sangue. $\bigcirc$ mesmo sucede com o resto dos círculos (amigos, colegas etc.). Nesse contexto estaria se configurando um tipo de sociedade em que há o risco da existência de formas paralelas, duais, de pertinência social. Por um lado, âmbitos 
em que predominarão as relações eletivas e especializadas e, por outro, âmbitos em que voltarão a se estabelecer solidariedades impostas por fatores adscritos. Além da análise de cada uma dessas possibilidades, o certo é que o papel e as formas de solidariedade serão o tema central na discussão sobre as alternativas de desenvolvimento social no futuro.

A formação do sentido de solidariedade está intimamente associada à formação do sentido de pertinência. Respectivamente, o desafio educativo implica desenvolver a capacidade de construir uma identidade complexa, uma identidade que contenha a pertinência a múltiplos âmbitos: local, nacional e internacional, político, religioso, artístico, econômico, familiar etc. A essência da cidadania moderna é, precisamente, a pluralidade de âmbitos de desempenho e a construção da identidade baseada nessa pluralidade e não em apenas um eixo dominante e excludente (Tedesco, 1995).

Em termos educacionais, o desenvolvimento desse sentido plural de pertinência, que combine a adesão e a solidariedade local com a abertura às diferenças, implica introduzir maciçamente nas instituições escolares a possibilidade de realizar experiências que fortaleçam esse tipo de formação. Relativamente a isso, todos os diagnósticos indicam a existência de um significativo déficit de experiências democráticas e pluralistas na sociedade. A escola é um âmbito privilegiado para o desenvolvimento de experiências desse tipo, que possam ser organizadas com propósitos educativos.

Postular a necessidade de desenvolver esse conjunto de competências e capacidades é necessário, mas não suficiente. $O$ desafio para os educadores consiste, ademais, em definir os desenhos institucionais mais apropriados e elaborar as ferramentas técnicas e metodológicas mais eficazes para que esses objetivos superem a fase puramente retórica e se transformem em metas concretas de aprendizagem. Do ponto de vista institucional, é necessário discutir que tipo de escola e que articulações entre ela e a sociedade são as mais apropriadas para fazer face a tais desafios.

A escola tradicional esteve particularmente fechada ao contato com outras instituições e com outros atores sociais. Embora esse modelo possa ter sido o mais apropriado no momento de construção dos Estados nacionais, em que a escola aparecia como a instituição que devia superar os particularismos, atualmente ela já não pode manter-se isolada, ignorando as transformações que se produziram no âmbito da família, da empresa e dos meios de comunicação.

Em síntese, é preciso romper o isolamento institucional da escola, abrindo-a aos requerimentos da sociedade e redefinindo seus pactos com os outros agentes 
socializadores, particularmente a família e os meios de comunicação. Qual deveria pois, ser o papel específico da escola? No contexto da análise que efetuamos, parece necessário enfatizar a idéia de que a escola deve assumir uma parte importante da formação nos aspetos "duros" da socialização. Isso não significa reivindicar a rigidez, a memória, a autoridade etc., mas aceitar que sua tarefa é levar a cabo, de forma consciente e sistemática, a construção das bases da personalidade das novas gerações.

Em um mundo no qual a informação e os conhecimentos se acumulam e circulam através de meios tecnológicos cada vez mais sofisticados e poderosos, o papel da escola deve ser definido pela sua capacidade de preparar para o uso consciente, crítico, ativo dos aparatos que acumulam a informação e o conhecimento.

Neste sentido, parece que uma das pistas mais promissoras de trabalho para a escola é a que tem a ver justamente com a sua relação com o convívio, com as relações face a face, com a possibilidade de oferecer um diálogo direto, um intercâmbio com pessoas reais em que os instrumentos técnicos sejam o que são, instrumentos e não fins em si mesmos. $O$ clima das instituições escolares, diferenciadas segundo projetos pedagógicos e dotadas de significativos níveis de autonomia para poder conectar-se com o meio, constitui uma variável central para o desenvolvimento de um processo de socialização eficaz.

Mas assim como o modelo institucional tradicional não pode ser mantido nas atuais circunstâncias históricas, também é preciso advertir que um desenho institucional baseado somente na autonomia das escolas pode aumentar os riscos de segmentação. A autonomia deve ser um estímulo para a vinculação e não para o isolamento. A idéia de rede constitui uma forma fértil para estimular conexões entre as instituições escolares que superem o formalismo tradicional e permitam intercâmbios reais, tanto em nível local como nacional e internacional.

\section{REFERÊNCIAS BIBLIOGRÁFICAS}

BOLTANSKY, L; CHIAPELLO. E. Le Nouve/ esprit du capitalisme. Paris: Gallimard, 1999.

CASTEL, R. Les Métamorphoses de la question sociale: une cronique du salariat. Paris: Fayard, 1995.

CASTELLS, M. La Era de la información: economía, sociedad y cultura. Madrid: Alianza, 1997. V. I. La Sociedad red. V. II: El Poder de la identidad.

COHEN, D. Richesse du monde, pauvetré des nations. Paris: Flammarion, 1997. 
DELORS, J. La Educación encierra un tesoro. Paris: Unesco, 1996.

DRUCKER, P.F. Post-Capitalist society. New York: Harper Business, 1993.

FITOUSSI, J. P.; ROSANVALLON. P. Le Nouvel âge des inégalités. Paris: Seuil, 1996.

FOUCAULD, J. B.; PIVETEAU. D. Une société en quête de sens. Paris: Editions Odile Jacob, 1995.

FUKUYAMA, F. A Grande ruptura. Buenos Aires: Atlántida, 1999.

GORZ, A. Misères du présent, richesses du futur. Paris: Galilée, 1997.

HERRNSTEIN, R. ..; MURRAY. C. The Bell curve: intelligence and class structure in american life. New York: Free Press Paperbacks, 1994.

MINC, A. La Nueva idad media. Madrid: Temas de Hoy, 1994.

MORIN, E. La Tête bien faite: repenser la réforme, réformer la pensée. Paris: Seuil, 1999.

RAWLS, J. Teoría de la justicia. México: Fondo de Cultura Económica, 1978.

RIFKIN, J. The Biotech century: harnessing the gene and remaking the world. New York: J. P. Tarcher; Putnam, 1998.

ROSANVALLON, P. La Nouvelle question sociale: repenser l'état-providence. Paris: Seuil, 1995.

SCHNAPPER, D. La Communauté des citoyens: sur l'idée moderne de nation. Paris: Gallimard, 1994.

SENNETT, R. La Corrosión del carácter: las consecuencias personales del trabajo en el nuevo capitalismo. Barcelona: Anagrama, 2000.

TEDESCO, J. C. El Nuevo pacto educativo: ciudadanía y competitividad en la sociedad moderna. Madrid: Anaya, 1995.

THUROW, L. C. The Future of capitalism: how today's economic forces shape tomorrow's world. London: N. Brealey, 1996.

TOFFLER, A. El Cambio del poder. Barcelona: Plaza y Janés, 1990.

Recebido em: junho 2002

Aprovado para publicação em: junho 2002 